systems and several awareness-raising materials. Reporting on pesticide incidents to the Rotterdam Convention has the advantage of making those incidents known to the world by sharing information with other countries which experience the same problems with specific pesticide formulations and allowing them to see if risk management measures are properly taken into account at national level.

\section{5d ACTIVATING THE PRIVATE SECTOR IN SAFE WORK FOR YOUTH AGES 15-17}

Vicki Walker. Prime International

10.1136/oemed-2018-ICOHabstracts. 1355

Since 2002, global trends in child labour reveal a persistent prevalence of hazardous work by youth 15 to 17 due largely to working conditions that violate legal standards. Rather than address occupational safety and health (OSH) conditions and remove hazards in order to protect youth, companies and employers tend to mitigate risk in their supply chains, by 'over-correcting' and not allowing youth under 18 to work although those over 15 normally have a right to work in the context of country laws and core labour standards based on International Labour Organisation (ILO) Conventions 138 and 182.

This paper demonstrates how years of data highlighting child labour and hazardous conditions of work have resulted in preventing and scaring away employers from hiring or purchasing goods produced from any youth under 18. Through qualitative and quantitative research, we have explored options for addressing the risks of child labour and gaps in younger youth employment. Our focus was to determine how employers and farmers react to youth of legal working age. We researched reports on the topic, and met with over 100 employers, farmers and unionists. Nearly $90 \%$ of the situations and inquiries as part of the survey maintained that they do not allow anyone under 18 to work. Over 50\% are aware that youth under 18 may not work in hazardous conditions however, they are not willing nor have the resources to change the conditions to enable youth to work. This pushes the youth to work illegally somewhere else in hazardous conditions.

We discuss business-led standards and efforts to transition youth from exploitive, hazardous, or harmful labour into safe and prosperous production as key to addressing youth unemployment, low-end jobs, and hazardous child labour.

\section{USE OF A RISK ASSESSMENT TO PROMOTE FARMER'S HEALTH}

If McNamara*, 2p Griffin, ${ }^{3} \mathrm{~J}$ Phelan, ${ }^{3} \mathrm{~J}$ Kinsella. 'Teagasc- Agriculture and Food Development Authority, Kildalton, Co. Kilkenny, Ireland; ${ }^{2}$ Health and Safety Authority, Dublin 1, Ireland; ${ }^{3}$ School of Agriculture, University College Dublin, Ireland

\subsection{6/oemed-2018-ICOHabstracts.1356}

Introduction Research in Ireland has indicated that farmers as an occupational group have inferior health outcomes. To assist with addressing this issue, health issues were included in a pilot Risk Assessment (RA) and associated half-day training course being evaluated for the agriculture sector under $\mathrm{OSH}$ legislation. The health RA template required a farmer to specify missing health controls. Farmers could complete the RA document with or without half-day training. At training guidance on health issues was provided using a DVD presented by a medical doctor. This paper provides evaluation on the health related controls specified in the RA for action and opinions of training provided.

Methods RA documents were obtained from farmers who completed it with $(n=335)$ and without $(n=140)$ training and health controls specified for action were tabulated. Opinions were obtained from both farmers $(n=291)$ and trainers $(n=51)$ on the health element of RA training delivered using a Likert-type question with a 5 point scale, with 5 the most positive response. Trainers had the option of additionally providing a comment.

Results A total of 0.32 and 0.14 controls per RA document were specified when completed with or without training. Controls were in the following categories: preventing back injury $(2.4 \%)$; respiratory protection $(9.5 \%)$, preventing infection (17.6\%), noise exposure control (9.5\%), stress/personal health management (56.4\%) (obtaining a 1 st aid box made-up $80 \%$ of this category) and additional controls (4.8\%). The opinion of health messages delivered at training had a mean score of 3.9 among both farmer and trainer respondents. Additionally $25.5 \%$ of trainers commented positively on the benefit of health training.

Conclusion The study indicates low uptake of health practices by farmers following RA completion. Training increased the level of specification of controls. Feedback from both farmers and trainers related to the health messages delivered at training was positive.

\section{RISK FACTORS OF PESTICIDE POISONING AND CHOLINESTERASE INHIBITION WITH COTTON WORKERS FROM NORTH OF BENIN'REPUBLIC (BANIKOARA AND KANDI TOWNSHIPS)}

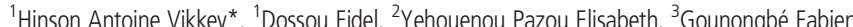
${ }^{4}$ Aguèmon Badirou, ${ }^{1}$ Hountikpo Hilaire, 'Lawin Hervé, ${ }^{1}$ Fayomi Benjamin. ${ }^{1}$ Unity of Teaching and Research in Occupational Health and Environment, FSS/UAC, Abomey-Calavi (Benin); 'Laboratoire de Recherche en Biologie Appliquée (LARBA), EPAC/UAC, AbomeyCalavi (Bénin): ${ }^{3}$ Département de Médecine et Spécialités Médicales, FM/Université de Parakou, Parakou (Bénin); ${ }^{4}$ Département de Santé Publique, unité de biostatistique FSS/UAC Abomey-Calavi (Bénin)

\subsection{6/oemed-2018-ICOHabstracts. 1357}

Introduction The use of pesticides saved millions of lives by killing the insects which are known to be potential vectors of disease, however, those pesticides have harmful effects on human health and on the environment public health and environmental problems caused using pesticides outweigh the benefits. The objective of this study is to assess the level of poisoning with the AChE test due to cotton producer's pesticide exposure in the biggest cotton production townships of northern Benin (Banikoara and Kandi), and to identifying the risk factors.

Method Through a cross sectional study, we recruited 190 pesticides sprayers for at least 5 years. They were submitted to a questionnaire and to acetylcholinesterase (AChE) test using the Test Mate model 400 devices (EQM Research Inc) 